\title{
Incidence of eyelid cancers in Singapore from 1968 to 1995
}

\author{
Sao-Bing Lee, Seang-Mei Saw, Kah-Guan Au Eong, Tat-Keong Chan, Hin-Peng Lee
}

\begin{abstract}
Aim-To describe the epidemiological characteristics of patients with eyelid malignancies seen in all hospitals in Singapore from 1968 to 1995.

Method-The Singapore Cancer Registry has been collecting epidemiological data of all cancers seen in Singapore since 1968. The data of all cases of Singapore residents with eyelid cancers diagnosed from 1968 to 1995 (ICD-9, sites 172.1 and 173.1) were retrieved for analysis.

Results-There were 162 male patients $(49.8 \%)$ and 163 females (50.2\%). The median age at diagnosis was 63 years in males and 66 years in females. The average annual age standardised incidence rate among male Singapore residents was 6.5 per million and 5.5 per million among female Singapore residents. Between 1993 and 1995, the average annual rate for females was 6.8 per million, compared with 3.1 per million between 1968 and 1972 . The most common cancer was basal cell carcinoma $(84.0 \%)$, followed by sebaceous adenocarcinoma $(10.2 \%)$ and squamous cell carcinoma $(3.4 \%)$.

Conclusion-The annual age standardised incidence for male residents has remained relatively stable. The incidence for female residents has shown a steady increase over the past 28 years. The incidence for males is generally higher than that for females. These expanded epidemiological characteristics may serve to provide a foundation to monitor future disease patterns and to promote further research into the aetiology of these cancers.

(Br f Ophthalmol 1999;83:595-597)
\end{abstract}

Cancer remains an important cause of death in Singapore although the incidence has tended to level off in recent years. ${ }^{1}$ Eyelid tumours are by far the most common neoplasms encountered in clinical ophthalmic practice. They are estimated to represent more than $90 \%$ of all ophthalmic tumours. ${ }^{2}$ Malignancies of the eyelid have been extensively reviewed in white patients but, to the authors' knowledge, there are no published epidemiological studies in South East Asia. As this information may be of interest to ophthalmologists, epidemiologists, pathologists, healthcare administrators, and other healthcare professionals, we have described the characteristics and incidence of eyelid cancers seen in Singapore from 1968 to 1995.

\section{Materials and methods}

We used the data of all eyelid cancer cases seen in Singapore from 1968 to 1995 in the Singapore Cancer Registry. The Singapore
Cancer Registry has collected data on cancers in Singapore since 1968. Data are acquired by physicians filling out a standardised form whenever a cancer is diagnosed clinically or on histopathology. Reports from all pathology laboratories are also requested and physicians are requested to provide data on cases that were not reported to the registry previously or when data are incomplete.

The Singapore Cancer Registry data cover all eyelid cancers seen in Singapore, both in Singapore residents and non-residents. In this report, we describe Singapore residents with cancers of the eyelid that were coded according to the International Classification of Diseases, Ninth Revision (ICD-9), ${ }^{3}$ sites 172.1 and 173.1. A total of 331 cases were retrieved, of which six $(1.8 \%)$ were not histologically verified. These six cases were omitted from the analysis. Calculations of age standardised and age specific incidence were made. The age standardised rates were derived by the direct method using the UICC "World" population. ${ }^{4}$ The local population denominators used are based on the Yearbook of Statistics, published yearly in Singapore. ${ }^{56}$

\section{Results}

A total of 325 cases were analysed of which 162 $(49.8 \%)$ were males and $163(50.2 \%)$ were females (Table 1). Of these, 296 (91.1\%) were Chinese, $17(5.2 \%)$ were Malay, $10(3.1 \%)$ were Indian, and two $(0.6 \%)$ were of other races. The median age at diagnosis was 63 years (range 14-89 years) for males and 66 years (range 24-98 years) for females. Ninety five per cent of the cases were 40 years of age and above. Basal cell carcinoma (BCC) was by far the most common eyelid malignancy, accounting for $84 \%(273 / 325)$ of all cases seen during this period. The other cancers seen were sebaceous adenocarcinoma (10.2\%), squamous cell carcinoma (SCC) $(3.4 \%)$, and malignant melanoma (MM) (1.2\%). Sebaceous adenocarcinoma occurred twice as frequently in females $(14.1 \%)$ as in males $(6.2 \%)$. All other cancers showed similar frequencies in both sexes (Table 2).

The average age standardised incidence for males over the 28 years was 6.5 per million, and for females, 5.5 per million. Figure 1 shows the trends for age standardised eyelid cancer incidence rates among Singapore residents from 1968 to 1995 . The average annual incidence is plotted for each of the 5 year periods, except for the last period, which is the average of 3 years. There has been a steady increase in rates in females from the first 5 year period to the 1988-92 period. In contrast, the rates in males have remained rather stable. 
Table 2 Frequencies of histology of eyelid cancer of Singapore residents in the Singapore Cancer Registry, 1968-95

\begin{tabular}{|c|c|c|c|c|c|}
\hline & Male $(n=162)$ & \multicolumn{2}{|c|}{ Female $(n=163)$} & \multicolumn{2}{|c|}{ Total $(n=325)$} \\
\hline Basal cell carcinoma & $141(87.1 \%)$ & \multicolumn{2}{|c|}{$132(81.0 \%)$} & \multicolumn{2}{|c|}{$273(84.0 \%)$} \\
\hline Sebaceous adenocarcinoma & $10(6.2 \%)$ & \multicolumn{2}{|c|}{$23(14.1 \%)$} & \multicolumn{2}{|c|}{$33(10.2 \%)$} \\
\hline Squamous cell carcinoma & $5(3.1 \%)$ & \multirow{2}{*}{\multicolumn{2}{|c|}{$6(3.7 \%)$}} & \multicolumn{2}{|c|}{$11(3.4 \%)$} \\
\hline Malignant melanoma & $2(1.2 \%)$ & & $2(1.2 \%)$ & \multicolumn{2}{|c|}{$4(1.2 \%)$} \\
\hline \multirow[t]{2}{*}{ Other diagnoses } & $4(2.4 \%)$ & \multicolumn{2}{|c|}{$0(0.0 \%)$} & \multicolumn{2}{|c|}{$4(1.2 \%)$} \\
\hline & $\begin{array}{l}\text { Chinese } \\
(n=296)\end{array}$ & $\begin{array}{l}\text { Malay } \\
(n=17)\end{array}$ & \multicolumn{2}{|c|}{ Indian $(n=10)$} & $\begin{array}{l}\text { Others } \\
(n=2)\end{array}$ \\
\hline Basal cell carcinoma & $245(82.8 \%)$ & $16(94.1 \%)$ & \multicolumn{2}{|c|}{$10(100 \%)$} & $2(100 \%)$ \\
\hline Sebaceous adenocarcinoma & $32(10.8 \%)$ & $1(5.9 \%)$ & \multicolumn{2}{|c|}{0} & 0 \\
\hline Squamous cell carcinoma & $11(3.6 \%)$ & \multirow{2}{*}{$\begin{array}{l}0 \\
0\end{array}$} & \multicolumn{2}{|l|}{0} & 0 \\
\hline Malignant melanoma & $4(1.4 \%)$ & & \multirow{2}{*}{\multicolumn{2}{|c|}{$\begin{array}{l}0 \\
0\end{array}$}} & 0 \\
\hline Other diagnoses & $4(1.4 \%)$ & 0 & & & 0 \\
\hline
\end{tabular}

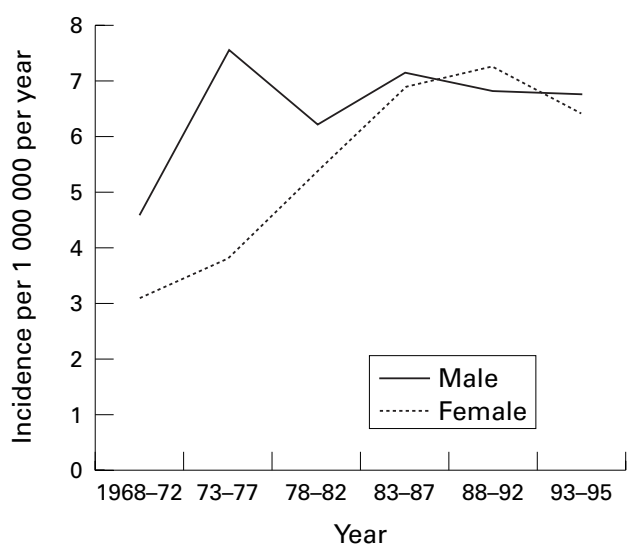

Figure 1 Age standardised ${ }^{\star}$ eyelid cancer incidence among Singapore residents from 1968 to 1995. ( ${ }^{\star}$ Standardised to UICC world population.)

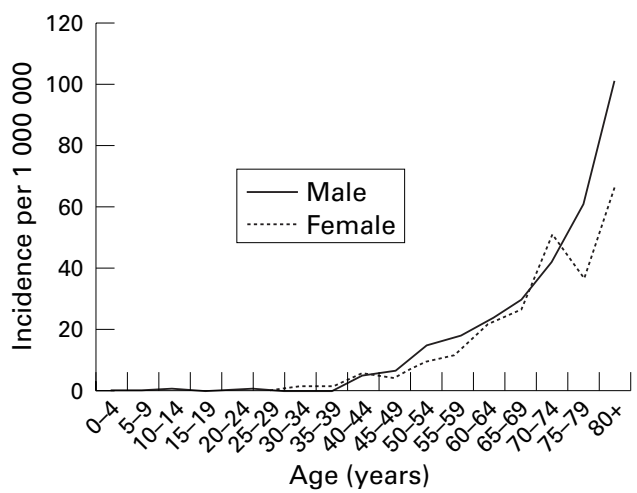

Figure 2 Average annual age specific eyelid cancer incidence among Singapore residents from 1969 to 1995.

Figure 2 presents the average annual age specific eye cancer incidence by sex among Singapore residents from 1968 to 1995. As seen in the graph, the incidence of eyelid cancers rises with age in both males and females.

\section{Discussion}

Eyelid cancer is a common problem in the West, representing about $10 \%$ of cancers in the head and neck region. ${ }^{7}$ About $5 \%$ to $9.2 \%$ of all skin cancers arise in the eyelid and cancers in this location account for at least $11 \%$ of all mortalities from skin malignancies. ${ }^{8}$ In Singapore, $1.9 \%$ of all melanomas and $8.5 \%$ of all non-melanoma cancers of the skin, recorded from 1968 to 1992 , arise in the eyelid. ${ }^{1}$
The cases described covers patients seen in all hospitals and clinics in Singapore. Cases recorded by the Singapore Cancer Registry are filed according to the National Registration Identity Card (NRIC) number. This is a unique number for each resident in Singapore, as a result, the possibility of duplicate recording is eliminated. These cases of cancer are sourced with all death records (on computer tape), from all hospital discharge summaries and from all pathology reports. This system ensures all cases of cancer seen in Singapore are recorded, hence the validity of data in this report.

The average annual age standardised incidence has increased steadily (Fig 1) over the years for females-from 4.6 per million in the 1968-72 period to 6.78 per million during 1993-5 period, with a peak of 6.84 per million from 1988 to 1992 . The rates for males have remained somewhat stable from 1978 to 1995 . It is plausible that the increase in rates seen in females is related to the increase of women in the workforce over the years. The participation rates of women in the Singapore workforce doubled from 1970 to 1992 , increasing from $24.6 \%$ in 1970 to $38.4 \%$ in 1976 and to $51.3 \%$ in $1992 .^{56}$ The increase of males in the workforce was less over this same time period, from $67.6 \%$ in 1970 to $79.9 \%$ in 1992 . The increase in the number of women in the workforce implies that more women are exposed to ultraviolet rays and hence the increase in incidence in eyelid cancers over the years since most eyelid cancers are sunlight related. The average incidence over the study period of 28 years is slightly higher in males (6.5 per million) than females (5.5 per million).

Malignancies of the eyelid are predominantly cancers of the skin. As with other skin tumours, malignant lesions of the eyelid increase with age (Fig 2). The median age of diagnosis was 64 years. This is similar to studies in Alabama ${ }^{9}$ and Sydney ${ }^{10}$; but lower than that seen in Philadelphia ${ }^{11}$ and in Japan, ${ }^{12}$ both of which reported a median age of diagnosis in the 70 s.

Skin tumours account for a large percentage of all cancers in the white population, but in Singapore this accounts for only $3.9 \%$ and $4.4 \%$ of all cancers for males and females respectively for the period 1988 to $1992 .{ }^{1}$ In the USA, epidemiological studies of eyelid cancers show that the population with these tumours is almost exclusively white. ${ }^{9}$ It is generally accepted that skin tumours are related to the duration of solar exposure and races with a lower degree of skin pigmentation tend to be at higher risk. ${ }^{13}$ This is also the case in this study, with the average age standardised incidence of eyelid cancers in Chinese being 7.8 per million, 5.5 per million in Malays, and 2.2 per million in Indians.

The most common primary malignancy was BCC $(84.0 \%)$, followed by sebaceous adenocarcinoma $(10.2 \%)$ and SCC (3.4\%) (Table 2$)$. In Philadelphia, the most common eyelid malignancy was also BCC $(82.4 \%)$, followed by sebaceous adenocarcinoma (6.4\%) and MM $(5.4 \%) .{ }^{11}$ BCC was also most commonly seen in 
Table 3 Histologies of eyelid cancers seen in various studies, in other parts of the world

\begin{tabular}{llllll}
\hline & $\begin{array}{l}\text { Singapore } \\
(1968-95) \\
(n=325)\end{array}$ & $\begin{array}{l}\text { Philadelphia } \\
(\text { USA })(1980-2) \\
(n=125)\end{array}$ & $\begin{array}{l}\text { Alabama (USA) } \\
(1958-88) \\
(n=117)\end{array}$ & $\begin{array}{l}\text { New Delhi } \\
\text { (India) (1982-92) } \\
(n=178)\end{array}$ & $\begin{array}{l}\text { Kyushu (fapan) } \\
(1960-81) \\
(n=52)\end{array}$ \\
\hline Basal cell carcinoma & $84.0 \%$ & $82.4 \%$ & $83.7 \%$ & $29.8 \%$ & $32.6 \%$ \\
Sebaceous adenocarcinoma & $10.2 \%$ & $6.4 \%$ & $1.7 \%$ & $32.6 \%$ & $13.5 \%$ \\
Squamous cell carcinoma & $3.4 \%$ & $2.4 \%$ & $10.3 \%$ & $28.1 \%$ & $48.1 \%$ \\
Malignant melanoma & $1.2 \%$ & $5.4 \%$ & $2.6 \%$ & $2.0 \%$ & $3.8 \%$ \\
\hline
\end{tabular}

Alabama, 83.7\%, between 1958 and 1988, but there was a higher proportion of SCC $(10.3 \%)$ and $2.6 \%$ for MM, but only $1.7 \%$ for sebaceous adenocarcinoma. ${ }^{9}$ There is a stark contrast in the proportion of histological diagnoses in a study in India, where the three most common cancers were seen in almost similar proportions-sebaceous adenocarcinoma $(32.6 \%)$, BCC $(29.8 \%)$, and SCC $(28.1 \%) .{ }^{14}$ This is supported in another Indian study where there was $38.8 \%$ of BCC, $27.1 \%$ of sebaceous adenocarcinoma, and $22.4 \%$ of SCC. ${ }^{15}$ BCC is also not the most common eyelid cancer in Japan. In one particular study over a 22 year period, there were $48.1 \%$ of SCC, $32.6 \%$ of BCC, and $13.5 \%$ of sebaceous adenocarcinoma. ${ }^{12}$ The results of these various studies are summarised in Table 3. However, in general, BCC is the most common skin cancer of the eyelid, accounting for $80-90 \%$ of cases. ${ }^{16} 17$

The average age at diagnosis of BCC of the eyelid is nearly $60 .{ }^{17} \mathrm{In}$ this study, the median age at diagnosis of BCC was 64 years of age (range 20-98 years). There were seven cases out of $273(2.6 \%)$ that were 30 years or younger at diagnosis. This shows that BCC does occur in young adults. These younger patients may have an inherited predisposition to cutaneous neoplasia. ${ }^{18} 19$

SCC is generally regarded as the second most common malignancy in the eyelid. ${ }^{20}$ The relative frequencies of this cancer in various studies show that there is a wide variation, as seen in Table 3, ranging from $2.4 \%$ in Philadelphia to $48.1 \%$ in a Japanese study. It is possible that the higher rates reported may be due in part to the tendency to overdiagnose SCC of the eyelid in the past as a result of its resemblance to other growths. ${ }^{21}$ Although it has been noted that this cancer is less frequently seen in individuals with a dark complexion, ${ }^{22}{ }^{23}$ it is interesting to note that the proportion of SCC is relatively high in India. The median age at diagnosis of SCC of the eyelid in this study was 65 years (range 47-89). This is comparable with that in other studies64.5 years (ranges $43-85$ years) in Washington $\mathrm{DC}^{24}$ and 72 years (range 55 to 96 years) in Philadelphia. ${ }^{23}$

In this study, sebaceous adenocarcinoma was found to be almost twice as common in females as in males. This preponderance of females has been shown in several studies. ${ }^{25-27}$ The average age at diagnosis is usually between 50 and 90 years of age. ${ }^{28}$ The median age of diagnosis in this study was 67 years (range 32-89 years).

In summary, the average annual age standardised incidence for females with eyelid malignancies in Singapore has risen over the years whereas the incidence for males has remained stable. Like other communities, eyelid cancers occur predominantly in the elderly. The majority of eyelid cancers are basal cell carcinomas. As eyelid cancer is the most common neoplasm seen in ophthalmic practice, this study has addressed the need to review the epidemiological pattern of this common group of ophthalmic malignancies in the South East Asian region.

1 Chia KS, Lee HP, Seow A, et al. Trends in cancer incidence in Singapore 1968-1992. Singapore: Singapore Cancer Registry, Report No 4,1996.

2 Kleinstein RN, Lehman HF. Incidence and prevalence of eye cancer. Am f Optom Physiol Optics 1977;54:49-51.

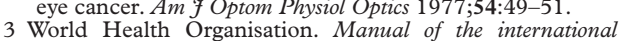
World Health Organisation. Manual of the international
statistical classification of diseases, injuries and causes of deaths. Vol 1. Geneva: WHO, 1977.

4 Parkin DM, Muir CS, Whelan SL, et al, eds. Cancer incidence in five continents. Volume VI. Lyons: IARC Scientific Publications No $120,1992$.

5 Khoo CK. Yearbook of statistics, Singapore, 1985/86. Singapore: Singapore National Printers, 1986.

6 Cheung P. Yearbook of statistics, Singapore, 1995. Singapore: Integrated Press, 1995

7 Lendrodt J. Principles of the surgical therapy of eyelid tumours. F Maxillofac Surg 1977;5:93-107.

8 Reifler DM, Hornblass A. Squamous cell carcinoma of the eyelid. Surv Ophthalmol 1986;30:349-65.

9 Swanson MW, Cloud G. A retrospective analysis of primary eye cancer at the University of Alabama 1958-1988. Part 2: Eyelid tumors. F Am Optom Assoc 1991;62:820-3.

10 Eyelid tumors. F Am Optom Assoc 1991;62:820-3. Francis IC, Benecke PS, Kappagoda MB. A ten-year hospital
survey of eyelid cancer. Aust f Ophthalmol 1984;12:121-7.

11 Turvey of eyelid cancer. Aust f Ophthalmol 1984;12:121-7. benign and malignant lesions. Ann Ophthalmol 1985;17: 704-7.

12 Abe M, Ohnishi Y, Hara Y, et al. Malignant tumour of the eyelid-clinical survey during a 22 -year period. $\mathcal{J p}_{p} \mathrm{f} O \mathrm{Oph}$ thalmol 1983;27:175-84.

13 Bergmanson JPG, Sheldon TM. Ultraviolet radiation revisited. CLAO F 1997;23:196-204.

14 Sihota R, Tandon K, Betharia SM, et al. Malignant eyelid tumors in an Indian population. Arch Ophthalmol 1996; 114:108-9.

15 Abdi U, Tyagi N, Maheshwari V, et al. Tumours of the eyelid: a clinicopathologic study. F Indian Med Assoc 1996; 94:405-9.

16 Lober CW, Fenske NA. Basal cell, squamous cell, and sebaceous gland carcinomas of the periorbital region. $\mathcal{F} \mathrm{Am}$ Acad Dermatol 1991;25:685-90.

17 Margo CE, Waltz K. Basal cell carcinoma of the eyelid and periocular skin. Surv Ophthalmol 1993;38:169-92.

18 Milstone EB, Helwig EB. Basal cell carcinoma in children. Arch Dermatol 1973;108:523-27.

19 Rahbari H, Mehregan AH. Basal cell epithelioma (carcinoma) in children and teenagers. Cancer 1982;49: 350-3.

20 Mamalis N, White G, Pedersen D, et al. Malignant lesions of the eyelid. Am Fam Physician 1989;39:95-102.

21 Kwitko ML, Boniuk M, Zimmerman LE. Eyelid tumors with a reference to lesions confused with squamous cell carcinoma. I. Incidence and errors in diagnosis. Arch Ophthalmol 1963;69:693-7.

22 Fayos JV, Wildermuth O. Carcinoma of the skin of the eyelids. Arch Ophthalmol 1962;67:298-302.

23 Dailey JR, Kennedy RH, Flaharty PM, et al. Squamous cell carcinoma of the eyelid. Ophthal Plast Reconstr Surg 1994;10:153-9.

24 Caya JG, Hidayat AA, Weiner JM. A clinicopathologic study of 21 cases of adenoid squamous cell carcinoma of the eyelid and periorbital region. Am $\mathcal{F}$ Ophthalmol 1985;99:2917.

25 Epstein GA, Putterman AM. Sebaceous adenocarcinoma of the eyelid. Ophthalmic Surg 1983;14:935-40.

26 Wolfe JT III, Yeatts RP, Wick MR, et al. Sebaceous carcinoma of the eyelid. Errors in clinical and pathologic diagnosis. Am F Surg Pathol 1984;8:597-606.

27 Rao NA, Hidayat AA, McLean IW, et al. Sebaceous carcinomas of the ocular adnexa. Hum Pathol 1982;13:11322.

28 Kass LG, Hornblass A. Sebaceous carcinoma of the ocular adnexa. Surv Ophthalmol 1989;33:477-90. 